\title{
Splanchnic Vein Thrombosis and MTHFR Mutation
}

\author{
Jaouad Yousfi ${ }^{*}$, Fatimazahra Bensalek ${ }^{1}$, Laila Benjilali $^{1}$, Lamiaa Essaadouni ${ }^{1}$ \\ ${ }^{1}$ Department of Internal Medicine, University Hospital of Mohammed VI, Marrakesh, Morocco
}

DOI: 1 10.36348/sjm.2021.v06i04.001 | Received: 13.03.2021 | Accepted: 17.04 .2021 | Published: 25.04 .2021

*Corresponding Author: Jaouad Yousfi

\section{Abstract}

Non-cirrhotic portal vein thrombosis is a rare condition. Constitutional thrombophilia, alone or with other risk factors, predisposes to splanchnic thrombosis. Methylenetetrahydrofolate reductase (MTHFR) mutations are associated with vascular diseases. We report an observation of a 48-year-old patient who was diagnosed with MTHFR mutation during the etiological workup of a mesenteric venous thrombosis.

Keywords: Portal thrombosis- MTHFR mutation -thrombophilia.

Copyright (C) 2021 The Author(s): This is an open-access article distributed under the terms of the Creative Commons Attribution 4.0 International License (CC BY-NC 4.0) which permits unrestricted use, distribution, and reproduction in any medium for non-commercial use provided the original author and source are credited.

\section{INTRODUCTION}

In 1995, Frosst et al., described the MTHFR gene, located on chromosome 1 , whose mutation induces three genotypes: CC (wild type), CT (heterozygous) and TT (homozygous). This mutation causes an alteration in the conversion of homocysteine to methionine, leading toits accumulation, and therefore be responsible for a mild to moderate hyperhomocysteinemia. Elevated plasma homocysteine levels increase the secretion of endothelin-1, causeendothelial cell injury, and decrease the secretion of endothelium-derived relaxing factors and prostaglandin, which leads to thromboembolic complications [1].

\section{CASE PRESENTATION}

A 48-year-old man presented with epigastric abdominal pain. The clinical examination found tenderness of the epigastrium, an anal fissure, without any hepatosplenomegaly. Abdominal ultrasound showed mesenteric veinous thrombosis.

The biological assessment showed a biological inflammatory syndrome (C-reactive protein at 69.67 $\mathrm{mg} / \mathrm{l}$, erythrocyte sedimentation rate at $65 \mathrm{~mm}$ ). The patient had negative serologies forbrucellosis, leishmaniasis, hepatitis B and $\mathrm{C}$. The haemogram and the bone marrow biopsy were normaland the JAK2 $\mathrm{V} 617 \mathrm{~F}$ mutation was not detected. The screening for anti-nuclear, anti-cardiolipins, anti-B2 glycoproteins Iantibodies and lupus anticoagulant was negative.
The constitutional thrombophilia assessment did not show protein $\mathrm{C}$ or $\mathrm{S}$ deficiency (Protein $\mathrm{C}$ at $106 \%(80-130)$ and Protein $S$ at $60 \%(70-130)$ ), nor was it the case for factor $\mathrm{V}$ Leiden and factor II mutations. The factor VIII was at $86 \%$ (70-140) andthe antithrombin III was at $85 \%(80-120)$. The serum homocysteine level was high at $16.48 \mu \mathrm{mol}(<10)$. He also had MTHFR C677T heterozygous mutation.

The patient was treated with anticoagulants: low molecular weight heparin followed by rivaroxaban $20 \mathrm{mg}$ daily.

The 3 months follow-up showed clinical and biological improvement. The C-reactive protein was at $8.76 \mathrm{mg} / \mathrm{l}$ (vs 69.67 on admission), and the abdominal palpation was normal. No bleeding events were observed.

\section{DISCUSSION}

Portalvein thrombosis (PVT) is a relatively common complication in cirrhotic patients, with a prevalence that varies between 0.6 and $26 \%[2,3]$.

PVT can also occur in absence of an overt liver disease, due tolocoregional (70 of cases \%), and general aetiologies (30\%) [4].

Constitutional prothrombotic disorders such as antithrombin III, protein $\mathrm{C}$ and $\mathrm{S}$ deficiency, the factor $\mathrm{V}$ Leiden mutation, hyperhomocysteinemia and MTHFR mutation contribute to thrombotic manifestations such as PVT [5]. 
Jaouad Yousfi et al.; Saudi J Med, Apr, 2021; 6(4): 63-64

Methylenetetrahydrofolate reductase (MTHFR) is an important enzyme of the folate pathway. The presence of its mutation alters folate metabolism and induces a moderate increase in the plasma homocysteine concentrations. Moderate hyperhomocysteinemia is considered by most authors to be a vascular risk factor for both arterial and venous disease.The MTHFR C677T and A1298 Cpolymorphism gene mutation is associated with thromboembolic disease in homozygous and heterozygous carriers, even with normal blood homocysteine levels $[6,7]$.

According to three prospective studies, the presence of a homozygous or heterozygous MTHFR mutation represents a thromboembolic risk factor in cirrhotic and non-cirrhotic patients. Where as in the same patients, the role of the factor Vleiden and prothrombin mutation is less important [8-10].

The MTHFR mutation is also implicated in the occurrence of thrombosis at other sites. According to Ely, in a series of 34 cases of severe pulmonary embolism, 8 cases of MTHFR mutation were found (1 homozygous, 7 heterozygous) [3].

Rozen et al., reported that the MTHFR C677T mutation (homozygous or heterozygous) seems to increase the risk of cerebral venous thrombosis or pulmonary embolism in the presence of other risk factors $[11,12]$.

\section{CONCLUSION}

The etiological workup of non-cirrhotic portal veinous thrombosis should be exhaustive and must include the search for the MTHFR mutation which is a genetic thromboembolic risk factor with or without hyperhomocysteinemia.

\section{REFERENCES}

1. Frosst, P., Blom, H. J., Milos, R., Goyette, P., Sheppard, C. A., Matthews, R. G., ... \& Rozen, R. (1995). A candidate genetic risk factor for vascular disease: a common mutation in methylenetetrahydrofolate reductase. Nature genetics, 10(1), 111-113.

2. Yerdel, M. A., Gunson, B., Mirza, D., Karayalçin, K., Olliff, S., Buckels, J., ... \& Pirenne, J. (2000). Portal Vein Thrombosis In Adults Undergoing Liver Transplantation: Risk Factors, Screening, Management, and

Outcome1. Transplantation, 69(9), 1873-1881.

3. Francoz C, Belghiti J, Vilgrain V, Sommacale D, Paradis V, Condat B, Denninger MH, Sauvanet A,
Valla D, Durand F. Splanchnic vein thrombosis in candidates for liver transplantation: usefulness of screening and anticoagulation. Gut. 2005 May 1;54(5):691-7.

4. Plessier, A., Darwish- Murad, S., HernandezGuerra, M., Consigny, Y., Fabris, F., Trebicka, J., ... \& European Network for Vascular Disorders of the Liver (EN- Vie). (2010). Acute portal vein thrombosis unrelated to cirrhosis: a prospective multicenter follow- up study. Hepatology, 51(1), 210-218.

5. Derman, B. A., \& Kwaan, M. H. C. (2015). Risk factors, diagnosis, management, and outcome of splanchnic vein thrombosis: a retrospective analysis. infection, 1, 2.

6. Zheng YZ, Tong J, Do XP, Pu XQ, Zhou BT. Prevalence of methylenetetrahydrofolate reductase C677T and its association with arterial and venous thrombosis in the Chinese population. British journal of haematology. 2000 Jun;109(4):870-4.

7. Liew, S. C., \& Gupta, E. D. (2015). Methylenetetrahydrofolate reductase (MTHFR) C677T polymorphism: epidemiology, metabolism and the associated diseases. European journal of medical genetics, 58(1), 1-10.

8. Pasta, L., Pasta, F., \& D'Amico, M. (2016). PAI-1 4G-4G, MTHFR 677TT, V Leiden 506Q, and prothrombin 20210A in splanchnic vein thrombosis: analysis of individual patient data from three prospective studies. Journal of clinical and experimental hepatology, 6(1), 10-14.

9. D’Amico, M., Sammarco, P., \& Pasta, L. (2013). Thrombophilic genetic factors PAI-1, MTHFRC677T, V Leiden 506Q, and prothrombin 20210A in noncirrhotic portal vein thrombosis and Budd-Chiari syndrome in a caucasian population. International journal of vascular medicine, 2013.

10. D'Amico, M., Pasta, F., \& Pasta, L. (2015). Thrombophilic genetic factors PAI-1 4G-4G and MTHFR 677TT as risk factors of alcohol, cryptogenic liver cirrhosis and portal vein thrombosis, in a Caucasian population. Gene, 568(1), 85-88.

11. Ely, S. F., \& Gill, J. R. (2005). Fatal pulmonary thromboembolism and hereditary thrombophilias. Journal of Forensic Science, 50(2), JFS2004315-8.

12. Rozen, R. (1997). Genetic predisposition to hyperhomocysteinemia: deficiency of methylenetetrahydrofolate reductase (MTHFR). Thrombosis and haemostasis, 78(1), 523-526. 